\title{
A percepção dos contadores públicos em relação às Normas Brasileiras de Contabilidade Aplicadas ao Setor Público (NBCASP)
}

\author{
Marcio Roberto Piccoli \\ Universidade do Oeste de Santa Catarina (UNOESC) \\ Universidade Regional de Blumenau (FURB) \\ Roberto Carlos Klann \\ Universidade Regional de Blumenau (FURB)
}

O estudo objetiva identificar a percepção dos contadores públicos em relação às Normas Brasileiras de Contabilidade Aplicadas ao Setor Público (NBCASP), a partir de um questionário estruturado, enviado aos profissionais dos municípios da região da Associação de Municípios do Meio Oeste (Ammoc), Santa Catarina. A pesquisa, do tipo descritiva, foi dividida em três blocos: o primeiro buscou identificar o perfil do profissional, no segundo abordou-se os problemas enfrentados pelos profissionais quanto à adaptação às normativas e, no terceiro, o entendimento sobre as NBCASP. O estudo revelou ainda que $50 \%$ dos entrevistados não possuem amplo conhecimento sobre as NBCASP. As maiores deficiências estão nos procedimentos a serem adotados a partir das normas 16.9 e 16.10 . Conclui-se, assim, que na percepção dos respondentes a nova contabilidade pública é importante para a transparência e controle das contas públicas, mas, por outro lado, os contadores ainda não estão aptos a elaborar e analisar as demonstrações contábeis.

Palavras-chave: contabilidade pública, normatização, controle contábil, sistema de informação, transparência governamental, accountability

\section{La percepción de contadores públicos en relación con las Normas Brasileñas de Contabilidad Aplicada al Sector Público (NBCASP)}

El estudio tiene como objetivo identificar la percepción de los contadores públicos sobre las Normas Contables Brasileñas Aplicadas al Sector Público (NBCASP) basado en un cuestionario estructurado enviado a los profesionales en los municipios de la región de la Asociación de Municipios del Medio Oeste (Ammoc), Santa Catarina. El estudio descriptivo se dividió en tres partes: la primera fue la de identificar el perfil profesional, la segunda

[Artigo recebido em março de 2014. Versão final em fevereiro de 2015.] 
trata de los problemas que enfrentan los profesionales para adaptarse a las normas y, en el tercero, la comprensión de NBCASP. El estudio también reveló que el 50\% de los encuestados no tienen un amplio conocimiento sobre NBCASP. Las principales debilidades están en los procedimientos para adopción a partir de las reglas 16.9 y 16.10 . Se concluye que los encuestados se dan cuenta de que la nueva contabilidad pública es importante para la transparencia y el control de las cuentas públicas, pero, por otro lado, los contadores no son capaces de preparar y analizar los estados financieros.

Palabras clave: contabilidad pública, normalización, control contable, sistema de información, transparencia gubernamental, accountability

\section{The public accountants perception in relation to the Brazilian Accounting Standards Applied to the Public Sector (NBCASP)}

The study aims to identify the perception of public accountants in relation to Brazilian Standards of Accounting Applied to the Public Sector (NBCASP), from a structured questionnaire sent to professionals in the municipalities of the region of the Association of Municipalities Meio-Oeste - Ammoc, Santa Catarina. The research, descriptive, was divided into three blocks: the first was to identify the professional profile, the second on the problems faced by professionals in adapting to regulatory and third, the understanding of NBCASP. The study also revealed that $50 \%$ of respondents do not have extensive knowledge about the NBCASP. The biggest shortcomings are in the procedures to be adopted from the patterns of 16.9 and 16.10. Concludes therefore that the perception of the new public accounting interviewed is important for transparency and control of public accounts, but on the other hand, the counters are not able to prepare and analyze financial statements.

Keywords: public accounting, regulation, accounting regulation, information system, government transparency, accountability 


\section{Introdução}

A classe vivenciou e experimentou o processo de convergência às Normas Internacionais de Contabilidade para entidades privadas, a qual se tornou realidade a partir de 2008. Como parte desse processo de mudança, o Conselho Federal de Contabilidade (CFC) criou, juntamente com outras entidades de representação, o Comitê de Pronunciamentos Contábeis (CPC), órgão esse responsável pela convergência das normas contábeis brasileiras às normas internacionais, colocando assim a contabilidade brasileira no cenário internacional, em conformidade com as normas editadas pelo International Accounting Standards Board (IASB).

Em 2008, juntamente com o processo de convergência da contabilidade privada, o CFC, com o envolvimento de especialistas do setor, iniciou os debates com audiências públicas, no sentido de convergir a contabilidade aplicada ao setor público aos padrões internacionais, em conformidade com as Normas Internacionais de Contabilidade Aplicadas ao Setor Público (IPSAS), editadas pelo International Federation of Accountants (IFAC), a fim de alterar a metodologia contábil adotada pela Lei $n$ o 4.320/64.

Por meio da Portaria MF no 184 de 25/08/2008, editada pelo Ministério da Fazenda, foram estabelecidas as diretrizes a serem observadas no setor público quanto aos procedimentos, práticas, elaboração e divulgação das demonstrações contábeis, de forma a torná-los convergentes com as normas internacionais de contabilidade aplicadas ao setor público.

A partir do Decreto no 6.976, de 07/10/2009, o qual dispõe sobre os objetivos da contabilidade no âmbito federal, visando estabelecer a padronização e a consolidação das contas nacionais e, entre outros objetivos, a busca pela convergência aos padrões internacionais, é que a Secretaria do Tesouro Nacional (STN) intensificou seus estudos e normatizações do setor.

Desse processo, foram editados os novos planos de contas (PCASP) e manuais de contabilidade aplicada ao setor público (MCASP), a fim de auxiliar os profissionais na execução das atividades.

Em 21/11/2008, alinhado aos objetivos do decreto, o Conselho Federal de Contabilidade (CFC) editou 10 primeiras normas aplicadas ao setor público. A décima primeira foi publicada em 2011. Já em 2010, seguindo o processo de convergência, o CFC editou um livro com a tradução de 31 normas internacionais (IPSA), as quais futuramente se juntarão às normas já editadas pelo CFC.

Facultativas em 2009, as 10 NBCASPs entraram em vigor de forma obrigatória em janeiro de 2010, tendo como objetivo maior focar nas demonstrações da situação patrimonial e o resultado do ente público, diferentemente da Lei no 4.320, de 
1964, que historicamente foi vista como uma contabilidade de acompanhamento meramente orçamentário. Juntamente com a elaboração das NBCASPs pelo CFC, a STN iniciou seus trabalhos de normatização do setor público, com estimativa de que até 2014 todos os entes da Federação e o Distrito Federal deverão estar adequados às novas normas. Na linha de frente dessa mudança, está o contador público, responsável por interpretar as normatizações e operacionalizar os registros contábeis decorrentes dos fatos ocorridos.

Estudos como os de Darós e Pereira (2009), Riberio Filho et al. (2009), Vicente et al. (2011) e Souza et al. (2012) dizem respeito somente às alterações trazidas pelas novas normativas, comparando-se às legislações anteriores. Gusmão et al. (2010) estudaram a relação da NBCASP 16.6, especialmente a Demonstração do Fluxo de Caixa relacionada ao Balanço Financeiro, exigido pela Lei $n^{\circ} \cdot 4.320 / 64$. Dessa forma, apresenta-se como lacuna de pesquisa a percepção do contador público diante das mudanças que estão ocorrendo. Os estudos anteriores não investigaram essa percepção, que pode ser importante para demonstrar, na visão dos profissionais, as dificuldades encontradas a partir da nova contabilidade pública, bem como qual a perspectiva de futuro e de valorização desse profissional.

Neste contexto, apresenta-se a seguinte problemática de estudo: qual a percepção dos contadores públicos sobre as normas brasileiras de contabilidade aplicadas ao setor público (NBCASP)? A pesquisa tem por objetivo identificar a percepção dos contadores públicos em relação às normas brasileiras de contabilidade aplicadas ao setor público (NBCASP), com base em três áreas: sistema de informação, atualização profissional e a mudança de cultura operacional.

A adoção das NBCASPs representa uma mudança significativa nas práticas contábeis aplicadas ao setor público, ou seja, procedimentos contábeis como registro de provisões e de depreciação de bens passarão a ser obrigatórios a partir de sua adoção. Assim, os profissionais contábeis envolvidos nesse processo precisam estar atentos a essas mudanças e buscar se adequarem à nova normatização, que é discutida na seção seguinte, juntamente com alguns estudos anteriores sobre o tema.

\section{Referencial teórico}

Para dar suporte ao estudo, apresentam-se na revisão de literatura alguns estudos relacionados ao tema, bem como se abordam as principais mudanças trazidas pelas NBCASPs, as quais impactarão as atividades operacionais dos profissionais de contabilidade pública. Para Fragoso et al. (2012), estudos sobre convergência possuem um foco maior nas empresas de capital aberto. Para os autores, "há uma escassez de referências bibliográficas que tratam a convergência das normas de contabilidade no setor público" (Fragoso et al., 2012). 
Estudos recentes relacionados às NBCASPs dizem respeito somente a abordagens conceituais relativas às mudanças trazidas por essas normatizações. Darós e Pereira (2009), com base em uma pesquisa bibliográfica, apontaram, a partir das normas publicadas, as alterações trazidas ao setor público, bem como os desafios a serem enfrentados. Concluem que esse processo foi um avanço para a contabilidade pública no que se refere a maior transparência e, principalmente, a mudança em reconhecer ativos e passivos, caminhando na correção da visão contábil não mais ligada à execução orçamentária, assim como o observado por Xavier Júnior, Paulo e Silva (2010), em que ficou comprovado que as novas demonstrações contábeis, a partir das NBCASPs, proporcionaram uma melhoria da apresentação de informações econômicas, financeiras e patrimoniais dos entes públicos.

Por outro lado, Ribeiro Filho et al. (2009), ao abordarem a evolução da contabilidade financeira na perspectiva emancipatória de Erich Fromm, constataram que as principais dificuldades na implementação de novas teorias no setor público brasileiro estão associadas com mudanças de atitudes, tendo em vista a forte ligação dos profissionais contábeis com aspectos jurídicos, que nem sempre espelham os constructos basilares da Ciência Contábil. A partir dessa mudança de atitude, percebe-se que os responsáveis pela convergência das normas já identificaram um dos desafios a serem enfrentados pelos profissionais do setor público. Corroborando essa mesma perspectiva, Fragoso et al. (2012) identificaram que a convergência das NBCASPs às IPSAS apresenta em seu conteúdo aspectos mais relacionados a procedimentos operacionais, facilitando a partir da apresentação de demonstrativos específicos a accountability.

Semelhante a Xavier Júnior, Paulo e Silva (2010), Lopes et al. (2010) apresentaram um estudo sobre a complementaridade da Demonstração do Fluxo de Caixa em relação ao Balanço Financeiro do Governo do Estado de Pernambuco, em relação à NBCASP 16.6. A análise dos demonstrativos revelou que ambos são importantes para a tomada de decisão dos gestores e que são complementares, além de gerarem informações diferentes. Nesse sentido, um não pode ser substituído pelo outro, sob pena da perda de informações relevantes tanto para o processo decisório, como para os usuários da informação pública, revelando que as mudanças da contabilidade aplicada ao setor público vieram no intuito de trazer maior transparência à utilização dos recursos públicos, ampliando a accountability (Fragoso et al.,2012).

A accountability e a transparência do setor público são umas das características das NBCASPs, as quais, a partir do princípio da competência, é possível que melhorem as informações à tomada de decisões dos gestores. Na percepção de Vicente et al. (2011), as normas promoveram uma distinção entre orçamento público e a contabilidade a partir da adoção do regime de competência utilizado 
para os registros do patrimônio. Para os autores, as novas demonstrações contábeis ampliam a transparência fiscal dos governos, citando, por exemplo, a adoção de métodos de depreciação e a implantação de sistemas de custos, os quais contribuem para a eficiência no setor público.

Outros estudos também já realizados sobre o tema abordam principalmente as alterações trazidas pelas normativas. Souza et al. (2012) e Ciupak e Silva (2012), a partir de uma abordagem conceitual, desenvolveram seus estudos nas alterações trazidas pela adoção das NBCASPs em relação às legislações anteriores, em especial a Lei $n^{\circ} 4.320 / 64$, já Salaroli e Almeida (2014) analisaram o processo de elaboração das normas internacionais, enquanto Gama, Duque e Almeida (2014) concluíram que as normas brasileiras seguiram o processo de convergência a partir da abordagem middleup-down, ou seja, elaborados por atores intermediários, favorecendo todos os envolvidos no processo.

O item 2.1 tem por objetivo discutir as normas que entendemos serem as que mais impactaram as atividades operacionais dos contadores públicos.

\section{Normas de contabilidade aplicadas ao setor público (NBCASP)}

As NBCASPs surgiram a fim de harmonizar as práticas contábeis públicas brasileiras às normas internacionais e, por consequência, padronizar a contabilidade dos Municípios à dos Estados e da União a partir das normatizações adicionais editadas pela STN.

A partir das Resoluções CFC no 1.128 a 1.137, de 21 de novembro de 2008, bem como a Resolução no 1.268 de 10/12/2009, a qual altera, inclui e exclui itens das NBCASPs 16.1, 16.2 e 16.6, originou-se o conjunto das 10 primeiras normas - NBC T 16. Em 2011, regulamentada pela Resolução CFC no 1.366 de 25/11/2011, juntou-se ao rol das 10 normas já em vigor a NBC T 16.11, conforme apresentado no Quadro 1.

\section{Quadro 1: Relação das NBCASPs}

\begin{tabular}{|c|c|l|}
\hline No & $\begin{array}{c}\text { Resolução } \\
\text { CFC }\end{array}$ & \multicolumn{1}{c|}{ Norma } \\
\hline NBC T 16.1 & $1.128 / 08$ & Conceituação, objeto e campo de aplicação \\
\hline NBC T 16.2 & $1.129 / 08$ & Patrimônio e sistemas contábeis \\
\hline NBC T 16.3 & $1.130 / 08$ & Planejamento e seus instrumentos sob o enfoque contábil \\
\hline NBC T 16.4 & $1.131 / 08$ & Transações no setor público \\
\hline NBC T 16.5 & $1.132 / 08$ & Registro contábil \\
\hline NBC T 16.6 & $1.133 / 08$ & Demonstrações contábeis \\
\hline NBC T 16.7 & $1.134 / 08$ & Consolidação das demonstrações contábeis \\
\hline
\end{tabular}




\begin{tabular}{|c|c|l|}
\hline No & $\begin{array}{c}\text { Resolução } \\
\text { CFC }\end{array}$ & \multicolumn{1}{c|}{ Norma } \\
\hline NBC T 16.8 & $1.135 / 08$ & Controle interno \\
\hline NBC T 16.9 & $1.136 / 08$ & Depreciação, amortização e exaustão \\
\hline NBC T 16.10 & $1.137 / 08$ & $\begin{array}{l}\text { Avaliação e mensuração de ativos e passivos em entidades do } \\
\text { setor público }\end{array}$ \\
\hline \multicolumn{2}{|c|}{ Resolução 1.268/09 } & Altera, inclui e exclui itens da NBC T 16.1, 16.2 e 16.6 \\
\hline NBC T 16.11 & $1.366 / 11$ & Sistema de informação de custos do setor público \\
\hline
\end{tabular}

Fonte: Adaptado de CFC (2012).

Apesar de todas as normas trazerem mudanças ao setor público, algumas impactaram mais significativamente as atividades operacionais do contador. Destaca-se o princípio da competência como uma das principais mudanças trazidas pelas novas normas, bem como outras que tratam do planejamento, transações com o setor público, demonstrações contábeis, depreciação, entre outras.

A adoção ao regime de competência possibilitará ao setor público registrar receitas e despesas conforme sua ocorrência e não mais quando do pagamento ou recebimento. Para o Conselho Federal de Contabilidade (CFC, 2012), a ausência de adoção desse regime possibilita que diversos ativos e passivos não sejam reconhecidos, prejudicando fortemente a evidenciação da situação financeira e dos resultados do exercício.

A NBC T 16.3: planejamento e seus instrumentos sobre o enfoque contábil, definiu planejamento como o processo contínuo e dinâmico voltado à identificação das melhores alternativas para o alcance da missão institucional, incluindo a definição de objetivos, metas, meios, metodologia, prazos de execução, custos e responsabilidades, materializados em planos hierarquicamente interligados. 0 que a norma prioriza são os acompanhamentos a serem realizados por meio dos instrumentos de planejamento elaborados pelo ente Público.

A Constituição Federal de 1988, em seu art. 165, estabelece como instrumentos de planejamento o plano plurianual, as diretrizes orçamentárias e os orçamentos anuais. Dessa forma, a NBCASP determina que os instrumentos de planejamento sejam acompanhados, contribuindo para as tomadas de decisões do administrador, gerando assim uma ferramenta de gestão eficiente dos recursos públicos.

Outra norma que trouxe uma mudança significativa foi a NBC T 16.4: transações no setor público. Essa norma classifica as transações do ente público em econômico-financeira e administrativa. A primeira é responsável pelos registros correspondentes às transações que afetam o patrimônio, em decorrência ou não da execução orçamentária, podendo provocar alterações qualitativas ou quantitativas. A segunda classificação refere-se a transações administrativas, ou seja, transações que não afetam o patrimônio. 
Para Lima, Santana e Guedes (2009), as mudanças trazidas pela NBC T 16.4, além de cumprir os aspectos legais e formais da Contabilidade Pública Brasileira, visa refletir a essência das transações governamentais e seu impacto no patrimônio.

Em relação à NBC T 16.6: Demonstrações Contábeis, pode-se afirmar que ela trouxe significativas mudanças nas demonstrações existentes e outras a serem incorporadas. Essa norma instituiu, além das demonstrações usuais, como o balanço patrimonial, o balanço financeiro, o balanço orçamentário e as demonstrações das variações patrimoniais, exigidas pela Lei no 4.320 de 1964, mais duas demonstrações contábeis obrigatórias: o fluxo de caixa e a demonstração do resultado econômico. Estabelece ainda a obrigatoriedade de o profissional elaborar notas explicativas, as quais deverão ser parte integrante das demonstrações contábeis.

Sobre a Demonstração dos Fluxos de Caixa, permite aos usuários projetar cenários de fluxos de caixa futuros e elaborar levantamentos sobre as possíveis mudanças em torno das finanças dos serviços públicos. Já a Demonstração do Resultado Econômico se assemelha à Demonstração do Resultado do Exercício, relatório mais que usual na contabilidade privada, a fim de demonstrar os resultados econômicos resultantes da ação do poder público no período.

Além das demonstrações exigidas pela NBC T 16.6, o Manual de Contabilidade Aplicada ao Setor Público (STN, 2012) estabelece a obrigatoriedade da escrituração da Demonstração das Mutações do Patrimônio Líquido (DMPL), obrigatória para as empresas estatais dependentes e para os entes que as incorporarem na consolidação das contas patrimoniais, seguindo os procedimentos estabelecidos na NBC T 16.7: Consolidação das Demonstrações Contábeis.

Muito discutida e debatida, a NBC T 16.9: Depreciação, Amortização e Exaustão trouxe aos profissionais da contabilidade pública uma nova visão contábil, agora sob o enfoque patrimonial. Estabelece os procedimentos e formas para o registro de depreciação, amortização e cotas de exaustão. O valor depreciado, amortizado ou exaurido deve ser apurado mensalmente e registrado nas contas de resultado do exercício. A depreciação deve ser reconhecida até que o valor contábil registrado no ativo seja igual ao valor residual.

Sob o enfoque patrimonial, a NBC T 16.10 (CFC, 2012, p. 40 e 41) se preocupou em estabelecer critérios e procedimentos para a avaliação e a mensuração de ativos e passivos integrantes do patrimônio de entidades do setor público, trazendo conceitos importantes para o processo de avaliação e mensuração de ativos e passivos.

Avaliação patrimonial: a atribuição de valor monetário a itens do ativo e do passivo decorrentes de julgamento fundamentado em consenso entre as partes e que traduza, com razoabilidade, a evidenciação dos atos e dos fatos administrativos. 
Reavaliação: a adoção do valor de mercado ou de consenso entre as partes para bens do ativo, quando esse for superior ao valor líquido contábil.

Redução ao valor recuperável (impairment): o ajuste ao valor de mercado ou de consenso entre as partes para bens do ativo, quando esse for inferior ao valor líquido contábil.

Valor de mercado ou valor justo (fair value): o valor pelo qual um ativo pode ser intercambiado ou um passivo pode ser liquidado entre partes interessadas que atuam em condições independentes e isentas ou conhecedoras do mercado. (CFC, 2012, p. 40 e 41).

O imobilizado será registrado pelo valor de aquisição, construção ou produção, sendo sujeito à depreciação/amortização quando tiver vida útil limitada. Se o imobilizado foi adquirido gratuitamente, deve ser feito um laudo de avaliação, por um técnico competente, para o seu registro. Caso no termo de doação conste algum valor patrimonial, esse poderá ser utilizado para a avaliação inicial (CFC, 2012).

Os bens incorpóreos destinados à manutenção das atividades públicas (ativos intangíveis) devem ser mensurados pelo valor de aquisição ou produção, sendo que os métodos utilizados para mensuração devem ser sempre evidenciados em notas explicativas. Tanto referente aos valores imobilizados quanto aos valores intangíveis, todos os gastos posteriores à aquisição, desde que exista a possibilidade de geração de benefícios econômicos futuros, devem ser incorporados ao valor do bem (CFC, 2012).

Os ativos que sofreram mudanças significativas em seus valores devem ser reavaliados anualmente, já os demais grupos de contas devem ser reavaliados, ao menos, a cada quatro anos. Para isso, deve ser utilizado, na data de encerramento do balanço, o valor justo ou o de mercado dos bens avaliados. Os acréscimos ou decréscimos ao valor do ativo devem ser registrados no resultado do período (CFC, 2012).

A normativa mais recente editada pelo CFC, a NBC T 16.11/2011, trouxe aos entes públicos regras básicas para mensuração e evidenciação dos custos no setor público, apresentada como Sistema de Informação de Custos do Setor Público (SICSP). Essa norma visa dar maior apoio à gestão por meio do registro, mensuração e evidenciação dos custos dos produtos, programas, serviços, ações e atividades dos entes públicos.

Um dos pilares do SICSP se refere aos métodos de custeio, que se definem como os métodos de apropriação dos custos ao objeto que está sendo custeado. Os principais métodos de custeio citados pela norma são: direto, variável, por absorção, por atividade e pleno.

Custeio direto é o custeio que aloca todos os custos - fixos e variáveis diretamente a todos os objetos de custo sem qualquer tipo de rateio ou apropriação. 
Custeio variável que apropria aos produtos ou serviços apenas os custos variáveis e considera os custos fixos como despesas do período.

Custeio por absorção que consiste na apropriação de todos os custos de produção aos produtos e serviços.

Custeio por atividade que considera que todas as atividades desenvolvidas pelas entidades são geradoras de custos e consomem recursos. Procura estabelecer a relação entre atividades e os objetos de custo por meio de direcionadores de custos que determinam quanto de cada atividade é consumida por eles (Resolução CFC no 1.366, 2011, p. 48).

Embora traga como um dos principais métodos de custeio, a NBC T 16.11 não faz referência conceitual ao método de custeio pleno. Para Martins (2003), "[...] consiste no rateio não só dos custos de produção, como também de todas as despesas da empresa, inclusive financeiras, a todos os produtos" (MARTINS, 2003, p. 220).

Concomitante às normatizações editadas pelo CFC, a STN, por meio de suas legislações, intensificou o processo de convergência, editando manuais e planos de contas aplicados ao setor público.

Percebe-se, pelo exposto da revisão de literatura, que não houve estudos buscando identificar a percepção dos contadores públicos quanto à implantação das NBCASPs. Dessa forma, o presente artigo procura preencher essa lacuna de pesquisa, ao apresentar a percepção de contadores públicos no Meio Oeste do Estado de Santa Catarina.

\section{Procedimentos metodológicos}

A pesquisa caracteriza-se de tipo descritivo, por descrever a percepção dos contadores públicos em relação às Normas Brasileiras de Contabilidade Aplicadas ao Setor Público (NBCASP). De acordo com Gil (1999), a pesquisa descritiva tem como "objetivo primordial a descrição de determinada população ou fenômeno ou o estabelecimento de relações entre variáveis" (GIL, 1999, p. 44).

A fim de cumprir o objetivo, a pesquisa foi desenvolvida a partir dos conceitos normativos publicados pelo CFC, bem como a respectiva legislação aplicável regulamentada pela Secretaria do Tesouro Nacional. O questionário foi dividido em três blocos com a finalidade de identificar os impactos e obstáculos trazidos pelo novo modelo de contabilidade pública.

O primeiro bloco procura identificar o perfil do profissional do setor público, com questões referentes a idade, gênero, tempo de profissão e nível de escolaridade. O segundo diz respeito aos problemas enfrentados pelos profissionais em relação aos sistemas de informação, responsáveis por boa parte das adequações a serem 
estruturadas, principalmente em relação às demonstrações contábeis. Nesse grupo, abordaram-se também os impactos da adequação ao cronograma publicado pelos próprios municípios. As perguntas desse bloco foram estruturadas para que o profissional identificasse, conforme uma escala Lickert de cinco pontos (discordo totalmente, discordo, indiferente, concordo e concordo totalmente), sua percepção sobre as mudanças.

No terceiro e último bloco, as questões se referem ao entendimento das normativas, ou seja, a partir dos novos conceitos, qual o entendimento do profissional em relação ao melhor desempenho de suas atividades, refletindo, em tempos de mudança, o aprendizado contínuo desse profissional. As perguntas desse bloco abordam as principiais mudanças trazidas pelas NBCASPs, sendo respondidas dentro da escala Lickert de cinco pontos semelhante à do segundo bloco.

A população e amostra correspondem aos contadores públicos das prefeituras e dos fundos a elas vinculados, bem como os profissionais das Câmaras Municipais da Região da Ammoc de Santa Catarina, totalizando 24 profissionais, conforme o Quadro 2.

A escolha da população e amostra deu-se pelo fato de que nessa região do Estado de Santa Catarina há poucos cursos ou treinamentos sendo realizados. Isso faz com que os profissionais dessa região tenham que se deslocar para outros municípios ou regiões metropolitanas do Estado, a fim de se manterem atualizados quanto às novas normas aplicadas à contabilidade pública.

Quadro 2: População e amostra

\begin{tabular}{|l|c|c|c|c|}
\hline Município & Prefeitura & Câmara & Fundo & Total \\
\hline Água Doce & 1 & 1 & & 2 \\
\hline Capinzal & 1 & 1 & & 2 \\
\hline Catanduvas & 1 & 1 & & 1 \\
\hline Erval Velho & 1 & & & 2 \\
\hline Herval do Oeste & 1 & 1 & & 1 \\
\hline Ibicaré & 1 & & & 4 \\
\hline Joaçaba & 1 & 1 & & 2 \\
\hline Lacerdópolis & 1 & & & 2 \\
\hline Luzerna & 1 & 1 & & 1 \\
\hline Ouro & 1 & 1 & & 2 \\
\hline Tangará & 1 & 1 & & 2 \\
\hline Treze Tílias & 1 & 1 & & 24 \\
\hline Vargem Bonita & 13 & 9 & & 2 \\
\hline Total & & & & 2 \\
\hline
\end{tabular}

Fonte: Elaborado pelos autores. 
A partir da escolha da população, o procedimento para coleta de dados se deu na forma de questionário estruturado, que foi enviado aos contadores das Prefeituras Municipais, Câmaras de Vereadores, Fundos e Autarquias dos Municípios identificados no Quadro 2, por meio da ferramenta Google Docs, no período de outubro a dezembro de 2014. Dos 24 questionários encaminhados, obteve-se retorno de 22 respostas.

\section{Limitações do estudo}

Como limitação do estudo, destaca-se a amostra dos 13 municípios pertencentes à Região da Ammoc, não sendo possível concluir que as repostas aqui apresentadas sejam consenso nas demais regiões do Estado de Santa Catarina, muito menos no Brasil de um modo geral, o que abre espaço para outras pesquisas na área.

\section{Análise dos resultados}

Inicialmente, procurou-se identificar o perfil dos profissionais, sendo os dados apresentados nas Tabelas 1 e 2. A partir dos dados da Tabela 1, identifica-se que a maioria dos respondentes possui idade acima dos 30 anos, sendo representado por 15 contadores, com participação de $68 \%$. Em relação ao gênero, o estudo mostra que na região estudada há um equilíbrio entre os profissionais homens e mulheres.

Tabela 1: Perfil dos respondentes

\begin{tabular}{l|c|c|c|c|c}
\hline Faixa Etária & Freq. & \% & Gênero & Freq. & $\%$ \\
\hline 20 a 30 nos & 4 & $18 \%$ & Masculino & 11 & $50 \%$ \\
\hline 31 a 40 anos & 8 & $36 \%$ & Feminino & 11 & $50 \%$ \\
\hline 41 a 50 anos & 7 & $32 \%$ & & & \\
\hline Acima de 50 anos & 3 & $14 \%$ & & & \\
\hline Total & 22 & $100 \%$ & Total & 22 & $100 \%$ \\
\hline
\end{tabular}

Fonte: Dados da pesquisa.

Ainda sobre o perfil dos respondentes, com base nos dados da Tabela 2, notase que $82 \%$ dos profissionais estão acima dos 10 anos de experiência na profissão. Desses, $41 \%$ ou nove respondentes trabalham no setor público há mais de 15 anos. A pesquisa revela também que os contadores públicos se preocupam com seu aprendizado, pois 54\% possuem algum tipo de especialização na área; por outro lado, não é possível afirmar que tais especializações referem-se exclusivamente à contabilidade pública. Dos pesquisados, $17 \%$ ou 4 profissionais são técnicos em contabilidade, demonstrando que a maioria dos que atuam no setor público já possui Graduação em Ciências Contábeis. 
Tabela 2: Perfil dos respondentes

\begin{tabular}{l|c|c|l|l|l}
\hline Tempo de Profissão & Freq. & $\%$ & Nível de Escolaridade & Freq. & $\%$ \\
\hline Até cinco anos & 4 & $18 \%$ & Técnico em Contabilidade & 4 & $17 \%$ \\
\hline De 06 a 10 anos & 6 & $27 \%$ & Graduação & 6 & $25 \%$ \\
\hline De 11 a 15 anos & 3 & $14 \%$ & Especialização & 13 & $54 \%$ \\
\hline Acima de 15 anos & 9 & $41 \%$ & Mestrado & 1 & $4 \%$ \\
\hline Total & 22 & $100 \%$ & Total & 24 & $100 \%$ \\
\hline
\end{tabular}

Fonte: Dados da pesquisa.

No segundo bloco da pesquisa, buscou-se saber qual a percepção dos profissionais sobre as mudanças ocorridas na contabilidade pública, cujos dados são analisados a partir da Tabela 3.

Tabela 3: Percepção do profissional sobre as mudanças

\begin{tabular}{l|c|c|c|c|c|c}
\hline & $\begin{array}{c}\text { Discordo } \\
\text { Totalmente }\end{array}$ & Discordo & Indiferente & Concordo & $\begin{array}{c}\text { Concordo } \\
\text { Totalmente }\end{array}$ & Total \\
\hline $\begin{array}{l}\text { 1. O sistema/programa de conta- } \\
\text { bilidade utilizado atende às atuais } \\
\text { mudanças da contabilidade pública. }\end{array}$ & 2 & 6 & - & 14 & - & 22 \\
\hline $\begin{array}{l}\text { 2. Tenho amplo conhecimento das } \\
\text { novas normas aplicadas ao setor } \\
\text { público. }\end{array}$ & - & 11 & 0 & 11 & - & 22 \\
\hline $\begin{array}{l}\text { O processo de mudança da conta- } \\
\text { bilidade pública dificultou/dificul- } \\
\text { tará o trabalho do contador. }\end{array}$ & 2 & 9 & 1 & 8 & 2 & 22 \\
\hline $\begin{array}{l}\text { 3. O processo de mudança valori- } \\
\text { zará o profissional da contabilida- } \\
\text { de pública. }\end{array}$ & - & 2 & 3 & 14 & 3 & 22 \\
\hline $\begin{array}{l}4 . \text { As mudanças trouxeram mais } \\
\text { responsabilidades para o contador } \\
\text { público. }\end{array}$ & - & - & 1 & 12 & 9 & 22 \\
\hline \begin{tabular}{l} 
Total \\
\hline
\end{tabular}
\end{tabular}

Fonte: Dados da pesquisa.

$\mathrm{Na}$ Tabela 3, constata-se que 14 profissionais concordam que o sistema de informação utilizado atende às mudanças decorrentes da adoção das novas normas de contabilidade pública. Sobre o conhecimento das NBCASPs, há uma divisão, ou seja, 50\% concordam e 50\% discordam dessa afirmação, conforme item 2 da Tabela 3.

Quando questionados sobre a dificuldade do trabalho profissional a partir das mudanças, não há consenso entre os pesquisados (item 3). Oito respondentes afirmam que concordam, ou seja, o trabalho do profissional está ou estará revestido de certa dificuldade. Por outro lado, nove responderam que discordam dessa afirmação, entendendo que a contabilidade não será dificultada pela aplicação das novas normatizações. 
O item 4 da Tabela 03 busca identificar se a nova contabilidade valorizará o profissional do setor. Para 17 respondentes (77\%), o processo de mudança valorizará o contador público. Semelhante ao estudo de Pux (2012), os contadores da Prefeitura de Porto Alegre afirmaram que o momento atual é de valorização profissional, apesar de alguns problemas enfrentados pela profissão.

Para os respondentes, a nova contabilidade traz mais responsabilidade aos profissionais do setor, conforme afirmação de $95 \%$ dos pesquisados. De acordo com a Resolução CFC no 803/96, a qual aprova o Código de Ética do Profissional da contabilidade, todo profissional que exerce atividade contábil deve exercer a profissão com zelo, diligência, honestidade e capacidade técnica, observada toda a legislação vigente. Sob essa ótica, o momento atual da contabilidade pública é de observância às legislações aplicáveis, com foco na transparência social das informações, estando intrínseca a responsabilidade do profissional.

Para Silva Junior (2001), o grande desafio do contador público e do futuro contabilista no início do século XXI é saber lidar com sua responsabilidade fiscal e social perante o mercado consumidor de informações, cada dia mais exigente e analítico.

Depreende-se, assim, que os contadores públicos consideram que a nova contabilidade pública trouxe mais responsabilidade ao profissional, havendo maior valorização dessa profissão.

O terceiro bloco da pesquisa buscou identificar o entendimento do profissional contábil sobre as mudanças trazidas pela nova contabilidade pública, sendo os dados apresentados e analisados a partir das Tabelas 4 e 5. Na Tabela 4, são apresentados dados das normas na visão dos profissionais.

\section{Tabela 4: As normas na visão dos profissionais}

\begin{tabular}{l|c|c|c|c|c|c}
\hline & $\begin{array}{c}\text { Discordo } \\
\text { Totalmente }\end{array}$ & Discordo & Indiferente & Concordo & $\begin{array}{c}\text { Concordo } \\
\text { Totalmente }\end{array}$ & Total \\
\hline $\begin{array}{l}\text { O foco principal da nova contabili- } \\
\text { dade pública é a gestão patrimonial. }\end{array}$ & - & 3 & - & 10 & 9 & 22 \\
\hline $\begin{array}{l}\text { As NBCASPs não fazem menção ao } \\
\text { princípio da competência. }\end{array}$ & 5 & 9 & 1 & 7 & - & 22 \\
\hline $\begin{array}{l}\text { Com o advento das NBCASPs, a Lei } \\
\text { no 4.320/64 foi revogada. }\end{array}$ & 9 & 10 & 1 & 2 & - & 22 \\
\hline $\begin{array}{l}\text { Mesmo com as novas mudanças, } \\
\text { continuaremos a contabilizar } \\
\text { no exercício as receitas pela } \\
\text { arrecadação e as despesas pelo } \\
\text { empenho. }\end{array}$ & 2 & 7 & 1 & 9 & 3 & 22 \\
\hline $\begin{array}{l}\text { Estou apto a tomar decisões } \\
\text { referentes à vida útil e depreciação } \\
\text { de ativos. }\end{array}$ & 2 & 11 & 3 & 5 & 1 & 22 \\
\hline
\end{tabular}




\begin{tabular}{l|c|c|c|c|c|c}
\hline & $\begin{array}{c}\text { Discordo } \\
\text { Totalmente }\end{array}$ & Discordo & Indiferente & Concordo & $\begin{array}{c}\text { Concordo } \\
\text { Totalmente }\end{array}$ & Total \\
\hline $\begin{array}{l}\text { Estou apto para elaborar e analisar } \\
\text { as demonstrações contábeis. }\end{array}$ & 1 & 12 & 4 & 5 & - & 22 \\
\hline Total & 19 & 52 & 10 & 38 & 13 & - \\
\hline
\end{tabular}

Fonte: Dados da pesquisa.

A nova contabilidade pública tem como foco a gestão do patrimônio público, adotando o princípio da competência para receitas e despesas. Para $86 \%$ dos respondentes, o foco da contabilidade é, sim, a gestão patrimonial, correspondendo a 19 profissionais que concordam e concordam totalmente com essa afirmação.

Conforme respostas apresentadas no item 2 da Tabela 4, 31\% dos pesquisados ou sete profissionais concordam que as NBCASPs não fazem menção ao princípio da competência, o que pode ser considerado um indicador elevado, por se tratar de normativa em vigor desde 2009.

Para Land e Rocher (2011) em Vasconcelos et al. (2012), a adoção da contabilidade pelo regime de competência no setor público envolve a introdução ou mudança de tecnologias da informação, mudanças culturais, consideráveis investimentos em sistemas de informação e desenvolvimento de habilidades apropriadas de preparadores e usuários.

Para Amaral, Bolfe e Vicente (2013), as contribuições da academia para a compreensão do regime de competência aplicado ao setor público são bastante fragmentadas, o que pode tornar lento o avanço no tema.

O item 3 da Tabela 4 procurou identificar se o profissional tem a percepção de que as mudanças trazidas pelas normas afetarão o patrimônio da entidade, ou seja, que a mudança para o regime de competência fará com que as receitas e despesas passem a ser reconhecidas a partir da identificação do fato gerador de direitos e obrigações para com o ente.

Os resultados apontam que enquanto 12 respondentes concordam ou concordam totalmente com tal afirmativa, nove discordam ou discordam totalmente. Novamente em comparação com o item 2 da Tabela 3, os profissionais estão divididos quanto a essa mudança. Apesar dos respondentes afirmarem ter conhecimento das normas, percebe-se que, quando focado na parte prática, esse entendimento é minimizado.

Entre as mudanças trazidas pela nova contabilidade pública, o profissional terá que avaliar e depreciar o ativo imobilizado do ente público, conforme estabelecido na NBCASP 16.9 e normativas da Secretaria do Tesouro Nacional. Sobre essa nova metodologia de tratamento patrimonial (item 4), 13 profissionais ou $59 \%$ dos pesquisados ainda não se consideram aptos a tomarem decisões de vida útil de depreciação de ativos, $17 \%$ se mostraram indiferentes e $27 \%$ consideram-se aptos a tomar essas decisões. 
As dificuldades apresentadas pelos respondentes podem ser comparadas aos achados de Vicente, Morais e Platt Neto (2011), que identificaram que a reforma da contabilidade pública promoverá a devida distinção entre o orçamento público e a contabilidade. A adoção do regime de competência para a contabilização do patrimônio público e alterações no conteúdo das demonstrações contábeis ampliarão a transparência fiscal dos governos.

Alves e Roncalio (2012) afirmam que é fundamental compreender as iniciativas dos diversos atores envolvidos no caso da evidenciação patrimonial em Santa Catarina (Sistema Administrativo de Gestão Patrimonial e Secretaria de Estado da Fazenda), como um caminho à necessária mudança de cultura, a fim de adotar o novo padrão da contabilidade pública, conhecer o processo de discussão e implementação dos procedimentos de reconhecimento, reavaliação, redução do valor recuperável, depreciação, amortização e exaustão de ativos.

No que se refere à elaboração e análise das demonstrações contábeis, a pesquisa também identificou que $59 \%$ dos respondentes não estão aptos a realizar essas atividades. Considera-se essa informação importante, tendo em vista que a partir das NBCASPs em vigor os profissionais estão obrigados a elaborar notas explicativas. Para tanto, há a necessidade de interpretar e analisar essas demonstrações contábeis.

Estudos de Platt Neto, Cruz e Vieira (2006), Gallon et al. (2011) e De Benedicto et al. (2011) identificaram a falta de notas explicativas ou informações incompletas na evidenciação das demonstrações contábeis. Por outro lado, Meneses e Peter (2012) evidenciaram uma evolução na apresentação das notas após esse período.

Com base nas questões de pesquisa apresentadas na Tabela 5, buscou-se identificar o entendimento do profissional em relação a seis NBCASPs consideradas pelo estudo fundamentais para o desempenho do profissional do setor público.

Tabela 5: Entendimento das Normas NBC T 16.3, 16.4, 16.6, 16.7, 16.9 e 16.10

\begin{tabular}{|c|c|c|c|c|c|c|}
\hline & 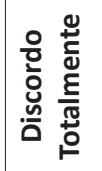 & 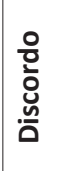 & 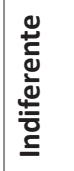 & 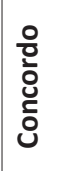 & 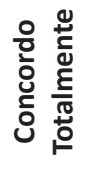 & $\begin{array}{l}\overline{\tilde{0}} \\
\text { 。ㅇ }\end{array}$ \\
\hline $\begin{array}{l}\text { Referente à NBC T 16.3, que trata do planejamento } \\
\text { e seus instrumentos sob o enfoque contábil, } \\
\text { houve a introdução das notas explicativas exigidas } \\
\text { a partir das demonstrações do exercício de } 2010 \text {. } \\
\text { Sob o enfoque do profissional, a introdução das } \\
\text { notas explicativas nas demonstrações contábeis } \\
\text { contribui para a qualidade da informação contábil } \\
\text { evidenciada pelas prefeituras e aumenta a } \\
\text { transparência. }\end{array}$ & - & 2 & 2 & 15 & 3 & 22 \\
\hline
\end{tabular}




\begin{tabular}{|c|c|c|c|c|c|c|}
\hline & 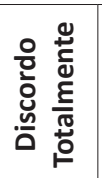 & 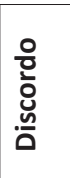 & 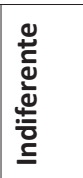 & 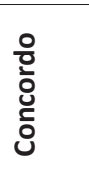 & 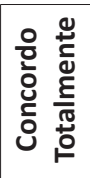 & $\begin{array}{l}\overline{\tilde{0}} \\
\stackrel{0}{\circ}\end{array}$ \\
\hline $\begin{array}{l}\text { De acordo com a NBC T 16.4, que trata das } \\
\text { transações no setor público, as variações } \\
\text { patrimoniais que afetam o patrimônio líquido } \\
\text { devem manter correlação com as respectivas } \\
\text { contas patrimoniais, através da vinculação por } \\
\text { meio de atributos. Essa vinculação por meio de } \\
\text { atributos vem auxiliar no controle contábil. }\end{array}$ & - & 2 & 4 & 14 & 2 & 22 \\
\hline $\begin{array}{l}\text { A NBC T } 16.6 \text { trata das demonstrações contábeis, } \\
\text { trazendo dois novos demonstrativos de cunho } \\
\text { gerencial, a demonstração do fluxo de caixa } \\
\text { e a demonstração do resultado econômico. A } \\
\text { exigência de apresentação desses demonstrativos } \\
\text { é importante para aumento da transparência das } \\
\text { contas públicas. }\end{array}$ & - & 1 & 2 & 18 & 1 & 22 \\
\hline $\begin{array}{l}\text { A NBC T } 16.7 \text { trata da consolidação das } \\
\text { demonstrações contábeis, tendo como seu } \\
\text { principal objetivo evitar a dupla contabilização de } \\
\text { receitas e despesas entre os entes de um mesmo } \\
\text { órgão. Essa norma é importante para aumento da } \\
\text { qualidade da informação contábil produzida pelo } \\
\text { ente público. }\end{array}$ & - & 2 & 2 & 16 & 2 & 22 \\
\hline $\begin{array}{l}\text { A NBC T } 16.9 \text { estabelece a adoção da prática do } \\
\text { registro contábil de depreciação, amortização e } \\
\text { exaustão no setor público. A prática desse registro } \\
\text { é relevante para o setor público. }\end{array}$ & - & 1 & 4 & 13 & 4 & 22 \\
\hline $\begin{array}{l}\text { A NBC T } 16.10 \text { trata da avaliação e mensuração } \\
\text { de ativos e passivos, estabelecendo regras para } \\
\text { reavaliações dos componentes patrimoniais, em } \\
\text { que se deve utilizar o valor justo ou o valor de } \\
\text { mercado na data de encerramento do balanço } \\
\text { patrimonial. É estipulado prazo de reavaliação } \\
\text { anual aos grupos de contas que podem variar } \\
\text { significativamente, e a cada quatro anos para os } \\
\text { demais grupos de conta. Essa posição é importante } \\
\text { para aumentar a qualidade da informação contábil } \\
\text { do ente público. }\end{array}$ & - & - & 1 & 17 & 4 & 22 \\
\hline Total & 0 & 8 & 15 & 93 & 16 & - \\
\hline
\end{tabular}

Fonte: Dados da pesquisa.

A partir das respostas em relação à NBC T 16.3, percebe-se que $82 \%$ ou 18 entrevistados concordam que a introdução de notas explicativas melhorará a informação contábil e aumentará a transparência do setor público. Os profissionais também entendem que as novas demonstrações contábeis (NBC T 16.6) vieram para aumentar a transparência das contas públicas. 
Para Morais e Platt Neto (2011), a reforma promovida pelas NBCASPs, à luz do processo de convergência, tem como objetivo o aumento da transparência entre outras informações patrimoniais. Para Raupp e Pinho (2012), uma das dimensões da accountability é a capacidade de proporcionar maiores condições de confiança entre governantes e governados, refletindo na transparência das ações governamentais.

Aliado à transparência e à evidenciação da contabilidade pública, Alves e Roncalio (2012) asseveram que o estudo da evidenciação contábil ganha relevância na medida em que se atribui à informação papel ímpar na sociedade de hoje, dada sua utilidade para o processo decisório. Os autores concluem que a abordagem social da contabilidade orienta para a divulgação da informação ao maior número possível de interessados.

Quanto à NBC T 16.4, a pesquisa mostrou que $18 \%$ consideram o atributo da conta indiferente e $72 \%$ concordam com a vinculação da conta por meio de atributo, vindo a melhorar o controle contábil do ente público. Para $81 \%$ dos pesquisados, a consolidação das contas evitará a dupla contabilização de receitas e despesas, melhorando a informação contábil produzida, conforme preconiza a NBC T 16.7.

Sobre a NBC T 16.9, 17 profissionais (77\%) entendem ser relevante o registro da depreciação, amortização e exaustão para a contabilidade, enquanto $18 \%$ manifestaram-se indiferentes sobre o assunto.

As alterações no conteúdo das demonstrações contábeis e a utilização da depreciação no setor público ampliarão a transparência fiscal (prestação de contas) dos governos, um dos pilares da governança no setor público (VICENTE; MoRAIS; PATT Neto, 2011). Para Meneses e Peter (2012), as notas explicativas trazem aspectos importantes que detalham os dados evidenciados nas demonstrações contábeis; entre eles, incluem-se os registros de depreciação, amortização e exaustão.

Corroborando as respostas à NBC T 16.9, 95\% dos respondentes consideram importante a NBC T 16.10, no que se refere à mensuração de ativos e passivos. Sobre as duas últimas normativas questionadas no estudo, cabe ressaltar que, conforme a Tabela 4, a maioria dos profissionais considera não estarem aptos a executar os procedimentos de vida útil e depreciação de ativos.

Mais estudos sobre a NBC T 16.9 e 16.10 precisam ser realizados a fim de identificar quais as dificuldades encontradas pelos profissionais em mensurar o valor de seus ativos, bem como a realização de avaliações conforme determina a normativa.

\section{Considerações finais}

O objetivo deste estudo foi identificar a percepção dos contadores públicos em relação às normas brasileiras de contabilidade aplicadas ao setor público (NBCASP), 
com base em três áreas: sistema de informação, atualização profissional e a mudança de cultura operacional. Para tal, foi realizada uma pesquisa de caráter descritivo, a partir de levantamento com 22 contadores públicos, com abordagem quantitativa.

A pesquisa mostrou que o perfil predominante dos profissionais públicos atuantes na Região da Ammoc do Estado de Santa Catarina é de indivíduos com idade acima dos 40 anos e que atuam há mais de 15 anos na área.

Constatou-se, também, que apenas a metade dos profissionais reconhece ter conhecimento amplo das normas aplicadas ao setor público. Por outro lado, a maioria entende que as normas são importantes para o setor; porém, seu entendimento ainda precisa ser aprimorado, como é o caso da aplicação de critérios de depreciação, elaboração das demonstrações e notas explicativas.

Observou-se ainda que, na visão da maioria dos pesquisados, as mudanças trouxeram mais responsabilidade e maior valorização ao profissional do setor. Conclui-se, dessa forma, que, apesar de os contadores serem responsáveis em suas atribuições, os pesquisados entendem que a responsabilidade aumentará e que sua atribuição será mais valorizada.

Sobre o entendimento das normas, percebeu-se que os contadores públicos consideram importantes todas as normas abordadas no estudo. Ao relacionar os resultados da Tabela 5 com os da Tabela 4, conclui-se que, apesar de considerarem as demonstrações contábeis e as notas explicativas importantes para a informação e a transparência da informação pública, a maioria dos pesquisados ainda não está apta a elaborar e analisar tais demonstrações, bem como à aplicação das principais NBCTs abordadas na pesquisa.

Por fim, denota-se que os profissionais pesquisados entendem ser importantes as mudanças ocorridas no setor público. No entanto, apesar de as normas estarem em vigor desde 2009, eles ainda não se sentem aptos a realizar alguns procedimentos fundamentais para a evidenciação patrimonial da entidade.

Assim, respondendo à questão de pesquisa, conclui-se, de forma geral, que os contadores públicos investigados reconhecem a importância das novas normas contábeis aplicáveis ao setor público. Contudo, admitem que ainda não estão totalmente preparados para implementá-las em sua totalidade. Além disso, o que é mais preocupante nos resultados encontrados é que alguns contadores pesquisados não demonstraram entendimento correto de algumas normas, o que pode prejudicar a qualidade das informações divulgadas relativas ao ente público.

Sugere-se, para futuras pesquisas, a busca por informações que identifiquem, de modo mais específico, as razões para a falta de preparo alegada por alguns respondentes para a adoção das NBCASPs. Além disso, novos estudos com contadores 
públicos de outras regiões ou de outros estados poderiam ser desenvolvidos, a fim de confirmar ou não os resultados encontrados nesta pesquisa.

\section{Referências}

Alves, J. L.; Roncalio, M. P. Evidenciação patrimonial no Estado de Santa Catarina: desafios e resultados da adoção das normas de contabilidade aplicadas ao setor público. In: CONGRESSO DA ASSOCIAÇÃO NACIONAL DE PROGRAMAS DE PÓS-GRADUAÇÃO EM CIÊNCIAS CONTÁBEIS, 6., 2012, Florianópolis. Anais eletrônicos... Florianópolis: 2012. Disponível em: <https://www.furb.br/especiais/ download/620591-473821/CUE\%20217.pdf>. Acesso em 06 ago. 2013.

Amaral, N. A. L; Bolfe, C; Vicente, E. F. R. A "torre de babel" dos estudos sobre o regime de competência no setor público brasileiro: os desencontros da discussão acadêmica. In: CONGRESSO DA ASSOCIAÇÃO NACIONAL DE PROGRAMAS DE PÓSGRADUAÇÃO EM CIÊNCIAS CONTÁBEIS, 7., 2013, Fortaleza. Anais eletrônicos.... Fortaleza: 2013. Disponível em: <http://www.furb.br/_upl/files/especiais/anpcont \%207/3806/cue\%20122.pdf?20130730100600>. Acesso em: 06 ago. 2013.

AVelino, B. C.; Colauto, R. D.; ANGOtTI, M. Política de evidenciação de informações do setor público no Estado de Minas Gerais. In: CONGRESSO USP DE CONTROLADORIA E CONTABILIDADE, 10, 2010, São Paulo. Anais... São Paulo: USP, 2010. CD- ROM.

BRASIL. Portaria Ministério da Fazenda no 25 de agosto de 2008. Dispõe sobre as diretrizes a serem observadas no setor público (pelos entes públicos) quanto aos procedimentos, práticas, laboração e divulgação das demonstrações contábeis, de forma a torná-los convergentes com as normas internacionais de contabilidade aplicadas ao setor público. Publicado no Diário Oficial da União em 26 de agosto de 2013. Disponível em: <http://www.fazenda.gov.br/portugues/legislacao/portarias/ 2008/portaria184.asp>. Acesso em: 05 abr. 2013.

BRASIL. Decreto Presidencial no 6.976 de 07 de outubro de 2009. Dispõe sobre o Sistema de Contabilidade Federal e dá outras providências. Publicado no Diário Oficial da União em 08 de outubro de 2009. Disponível em: <http://www.planalto. gov.br/ccivil_03/_Ato2007-2010/2009/Decreto/D6976.htm>. Acesso em: 05 abr. 2013.

BRASIL. Lei no 4.320, de 17 de março de 1964. Estatui normas gerais de direito financeiro para elaboração e controle dos orçamentos e balanços da União, dos Estados, dos Municípios e do Distrito Federal. Disponível em: <http://www.planalto. gov.br/ccivil_03/leis/14320compilado.htm>. Acesso em: 05 abr. 2013.

Conselho federal De Contabilidade. Normas brasileiras de contabilidade: contabilidade aplicada ao setor público: NBCs T 16.1 a 16.11. Conselho Federal de Contabilidade. Brasília: Conselho Federal de Contabilidade, 2012. (S.I). Disponível em: <http://50.97.105.38/ cfcor495/wordpress/wp-ontent/uploads/2013/01/Setor_ Público.pdf>. Acesso em: 05 abr. 2013.

Conselho Federal de Contabilidade. Normas Brasileiras de Contabilidade Aplicada ao Setor Público. NBCs T 16.1 a 16.11. Brasília: Conselho Federal de Contabilidade. 
2012. 51 p. Disponível em: < http://50.97.105.38/ cfcor495/wordpress/wp-content/ uploads/2013/01/Setor_P\%C3\%BAblico.pdf>. Acesso em: 13 Jun. 2013.

Conselho Federal de ContabilidAde. Resolução CFC no 803/96. Aprova o Código de Ética do Profissional Contador - CEPC. Disponível em: <www.cfc.org.br/sisweb/sre/ docs/br/sisweb/sre/docs/RES_803.DOC> Acesso em: 13 fev. 2015.

De Benedicto, S. C.; Rodrigues, A.; Penido, A. M. dA Silva; Stieg, C. M. A compreensão dos cidadãos acerca dos demonstrativos públicos: uma análise em três municípios mineiros. In: ENCONTRO NACIONAL DOS PROGRAMAS DE PÓS-GRADUAÇÃO EM ADMINISTRAÇÃO, 30., 2011. Anais... Rio de Janeiro: Anpad, 2011. CD-ROM.

CIUPAK, C; DA SILVA, B.A. As alterações da contabilidade pública e seus reflexos na gestão: uma abordagem conceitual. Revista Eletrônica Saber Contábil, v. 2, n. 2, mai./ ago. 2012. Disponível em: <http://revista.ulbrajp.edu.br/ojs/index.php/contabeis/ article/view/1716/483>. Acesso em: 10 abr. 2013.

DARÓS, L. L.; PEREIRA, A. S. Análise das normas brasileiras de contabilidade aplicadas ao setor público - NBCASP: mudanças e desafios para a contabilidade pública. In: CONGRESSO USP DE CONTROLADORIA E CONTABILIDADE, 9., 2009, São Paulo. Anais eletrônicos... São Paulo: USP, 2009. Disponível em: <http://www.congressousp. fipecafi.org/artigos92009/467.pdf>. Acesso em: 11 abr. 2013.

Fragoso, A.R. et al. Normas brasileiras e internacionais de contabilidade aplicadas ao setor público e o desafio da convergência: uma análise comparativa Ipsas e NBCTSP. Revista de Educação e Pesquisa em Contabilidade, v. 6, no 4, p. 434-447, out./dez. 2012.

FEIJó, P. H.; BugARIM, M. C. C. Portaria MF no 184/2008: um marco para a implantação do Novo Modelo de Contabilidade Aplicada ao Setor Público. Revista Brasileira de Contabilidade. São Paulo, v. 173, p. 79 a 89, set./out. 2008.

Gallon, A.V. et al. A compreensibilidade dos cidadãos de um município gaúcho acerca dos demonstrativos da Lei de Responsabilidade Fiscal publicados nos jornais. Revista de Contabilidade do Mestrado em Ciências Contábeis da UERJ (online), Rio de Janeiro, v. 16, n. 1, p. 79-96, jan./abr. 2011.

GAMA, J.R.; Duque, C. G.; ALMEIDA, J. E.F. Convergência brasileira aos padrões internacionais de contabilidade pública vis-à-vis as estratégias top-down e bottomup. Revista Administração Pública, v. 48, no 1, p. 183-206, fev. 2014.

GIL, A. C. Métodos e técnicas de pesquisa social. 5 ed. São Paulo: Atlas, 1999.

LiMA, D. V. DE; SAntAnA, C. M.; Guedes, M. A.; As Normas Brasileiras de Contabilidade aplicadas ao setor público e a legislação contábil pública brasileira: uma análise comparativa à luz da teoria contábil. Revista Contabilidade e Governança, Brasília, v. 12 , no 2, p. $15-23$, mai/ago 2009.

LOPES, J. E. et al. Um estudo sobre a complementaridade do fluxo de caixa e do balanço financeiro após a aprovação da NBCASP 16.6 para o setor público. In: CONGRESSO DA ASSOCIAÇÃO NACIONAL DE PROGRAMAS DE PÓS-GRADUAÇÃO EM CIÊNCIAS CONTÁBEIS, 4., Natal, 2010. Anais eletrônicos... Natal, 2010. Disponível em: <http://www.anpcont.com.br/site/docs/congressolV/02/CUE083.pdf $\geq$. Acesso em: 10 abr. 2013. 
Martins, Eliseu. Contabilidade de Custos. 9. ed. São Paulo: Atlas, 2003.

MoRAIS, L Morais; PLATT NETO, O. A. A reforma contábil promovida pelas NBCASP e o processo de convergência: implicações e perspectivas. In: ASSOCIAÇÃO NACIONAL DOS PROGRAMAS DE PÓSGRADUAÇÃO EM CIÊNCIAS CONTÁBEIS (ANPCONT), $5 .$, 2011, Vitória (ES). Anais... Vitória: ANPCONT, 2011.

Meneses, A. F. de; Peter, Maria da G. A. Evidenciação das demonstrações contábeis: estudo sob a óptica do processo de convergência das normas de contabilidade aplicadas ao setor público. CONGRESSO DA ASSOCIAÇÃO NACIONAL DE PROGRAMAS DE PÓSGRADUAÇÃO EM CIÊNCIAS CONTÁBEIS, 5., Florianópolis, 2012. Anais eletrônicos... Disponível em: <http://website.acep.org.br/2011/wp-content/uploads/2012/08/ http__webmail.acep_.org_.pdf>. Acesso em: 10 abr. 2013.

Platt Neto, O. A; Cruz, F. da; VieirA, A. L. Transparência das contas públicas: um enfoque no uso da internet como instrumento de publicidade na UFSC. Revista Contemporânea de Contabilidade, v. 1, n. 5, p. 135-146, jan./jun. 2006.

PuX, P. S. O processo de adoção das normas de contabilidade aplicadas ao setor público na gestão pública municipal de Porto Alegre. Trabalho de Conclusão de Curso: Especialização em Gestão Pública Municipal. UFRGS. Porto Alegre. 2012. Disponível em: <http://www.lume.ufrgs.br/handle/10183/71803>. Acesso em: 05 ago. 2013.

RAUPP, F. M.; PINHO, J. A. G.; Prestação de contas, transparência e participação em portais eletrônicos de câmaras municipais. In: CONGRESSO USP DE CONTROLADORIA E CONTABILIDADE, 12., São Paulo, 2012. Anais eletrônicos... São Paulo, 2012. Disponível em: <http://www.congressousp.fipecafi.org/artigos122012/65.pdf>. Acesso em: 06 ago. 2013.

Ribeiro Filho, J. F.; TAVARES, M. F. N.; AMARO, R. G.; LOPES. J. E. G. Evolução da contabilidade financeira na perspectiva emancipatória de Erich Fromm: o processo de construção das normas brasileiras de contabilidade aplicadas ao setor público NBCASP. Sociedade, Contabilidade e Gestão. Rio de Janeiro, v. 4, n. 1, jan/jun 2009.

SAlARoli, A. R.; AlmeidA, J. E.F. Análise do processo de elaboração das normas internacionais de contabilidade pública. In: CONGRESSO USP DE CONTROLADORIA E CONTABILIDADE, 14., 2014, São Paulo. Anais eletrônicos... São Paulo: USP, 2014. Disponível em: <http://www.congressousp.fipecafi.org/web/artigos142014/206. pdf>. Acesso em: 14 fev. 2014.

SILVA JUNIOR A. da. O perfil ideal do contador público frente à responsabilidade social. Economia \& Gestão, Belo Horizonte, v. 1, no 2, p. 69-84, jul./dez. 2001.

SouzA, H. V. de et al. Convergência das normas brasileiras de contabilidade do setor público às normas internacionais de contabilidade do setor público: um ensaio teórico. In: SEMINÁRIO EM ADMINISTRAÇÃO -FEA-USP. 15., São Paulo, 2012. Anais eletrônicos... São Paulo, USP, 2012. Disponível em: <http://www.ead.fea.usp.br/ semead/15semead/resultado/trabalhosPDF/373.pdf>. Acesso em: 10 abr. 2013.

VASCONCELOS et al. O regime de competência no setor público brasileiro - uma pesquisa empírica sobre a utilidade da informação contábil. In: CONGRESSO USP DE CONTROLADORIA E CONTABILIDADE, 12., São Paulo, 2012. Anais eletrônicos... São Paulo, 2012. Disponível em: < http://www.congressousp.fipecafi.org/artigos122012/151. pdf>. Acesso em: 06 ago. 2013. 
Vicente, E. F. R; Morais, L. M.; Platt Neto, O. A. A reforma na contabilidade pública brasileira e o processo de convergência: implicações e perspectivas. Revista de Informação Contábil (RIC), v. 6, no 2, p. 01-20, abr.jun./2012. ISSN 1982-3967.

XAVIER JúNIOR, Antônio E.; PAUlo, Edilson; Silva, José Dionísio G. Estudo sobre a capacidade informacional das novas estruturas das demonstrações contábeis aplicadas ao setor público. In: ASSOCIAÇÃO NACIONAL DOS PROGRAMAS DE PÓSGRADUAÇÃO EM CIÊNCIAS CONTÁBEIS (ANPCONT), 4., 2010, Natal (RN). Anais... Natal: ANPCONT, 2010.

Marcio Roberto Piccoli

É mestrando em Ciências Contábeis pela Fundação Regional de Blumenau (FURB) e Professor da Área de Ciências Sociais Aplicadas da UNOESC, Campus de Joaçaba. É também contador público. Contato: marcio.piccoli@unoesc. edu.br

Roberto Carlos Klann

É Doutor em Ciências Contábeis e Administração pela Universidade Regional de Blumenau. Atualmente é Professor do Programa de Pós-Graduação em Ciências Contábeis da Universidade Regional de Blumenau (FURB). Atua também como Professor Titular do Curso de Ciências Contábeis do Centro Universitário de Brusque (Unifebe). Contato: rklann@furb.br 
RSP 